\title{
Homonymous horizontal sectoranopia: report of four
}

\section{cases}

Michèle Grochowicki, Alain Vighetto

and/or MRI). An automatic static perimetry (AP) was undertaken in all cases and was compared in three with the Goldmann chart. The AP was mapped on the Vision Monitor (Metrovision) with a standardised programme. The static protocol included a suprathreshold strategy ( $4 \mathrm{~dB}$ above the theoretical luminance threshold) for the 94 points tested in the central $30^{\circ}$ and a laminal strategy for the foveolar point. ${ }^{12}$ Eight additional measurements were used to chart the blind spot contour. In two cases a study of the nerve fibre layer was carried out by a technique previously described. ${ }^{13}$

\section{Case reports}

CASE I

We examined a 66-year-old hypertensive woman six months after she suffered partially regressive Wernicke's aphasia. A Doppler investigation showed $30 \%$ stenosis of both carotid arteries. The visual acuity was right eye $20 / 25$, left eye $20 / 20$. The fundi were normal. Static automatic perimetry disclosed a small, right, horizontal, incongruous, homonymous scotoma, triangular in shape (Fig 1). A CT scan at the time of the stroke showed an ischaemic anomaly limited to the left anterior superficial sylvian territory (Fig 2). this exclusive anatomical correlation. Homonymous horizontal sectoranopia has also been described in lesions of the optic radiations $\mathrm{s}^{7-10}$ and of the occipital lobe. ${ }^{11}$

We have observed four new cases over the last three years, none of them showing a characteristic LGN alteration at least on CT scan or magnetic

Consultation de NeuroOphtalmologie, Hôpital Neurologique et NeuroChirurgical Pierre Wertheimer, 59 boulevard Pinel, 69003 Lyon, France M Grochowicki A Vighetto

Correspondence to: Dr $M$ Grochowicki. Accepted for publication 2 April 1991 resonance imaging (MRI). We believe that this visual field pattern is less rare than previously thought. ${ }^{10}$

\section{Patients}

During 1987-90 we examined seven patients with a homonymous horizontal sectoranopia. We selected four of them who had a neuroradiological investigation performed (CT scan
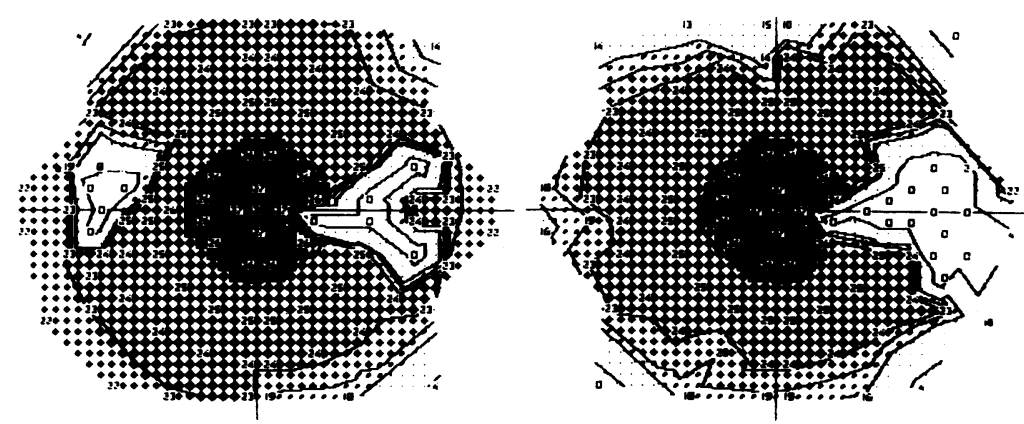

Figure 1 Case 1. Automatic static perimetry showing a right, horizontal, incongruous, triangular homonymous scotoma. (Shown in negative view, that is, densest scotomas are white.)
CASE 2

A 59-year-old man suddenly complained of severe headache associated with visual trouble.

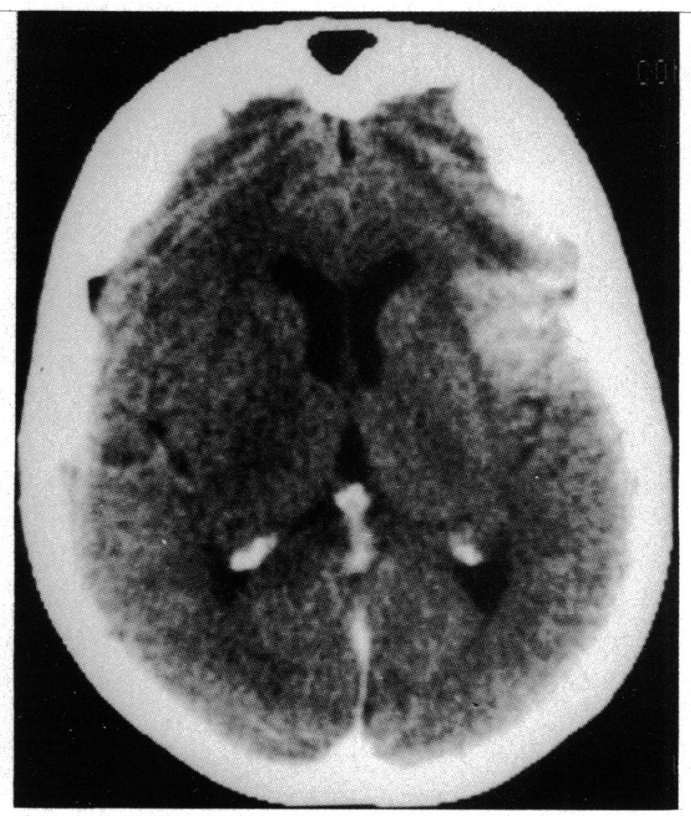

Figure 2 Case 1. Axial enhanced CT scan showing an ischaemic anomaly in the left anterior superficial sylvian territory (right side of picture). 

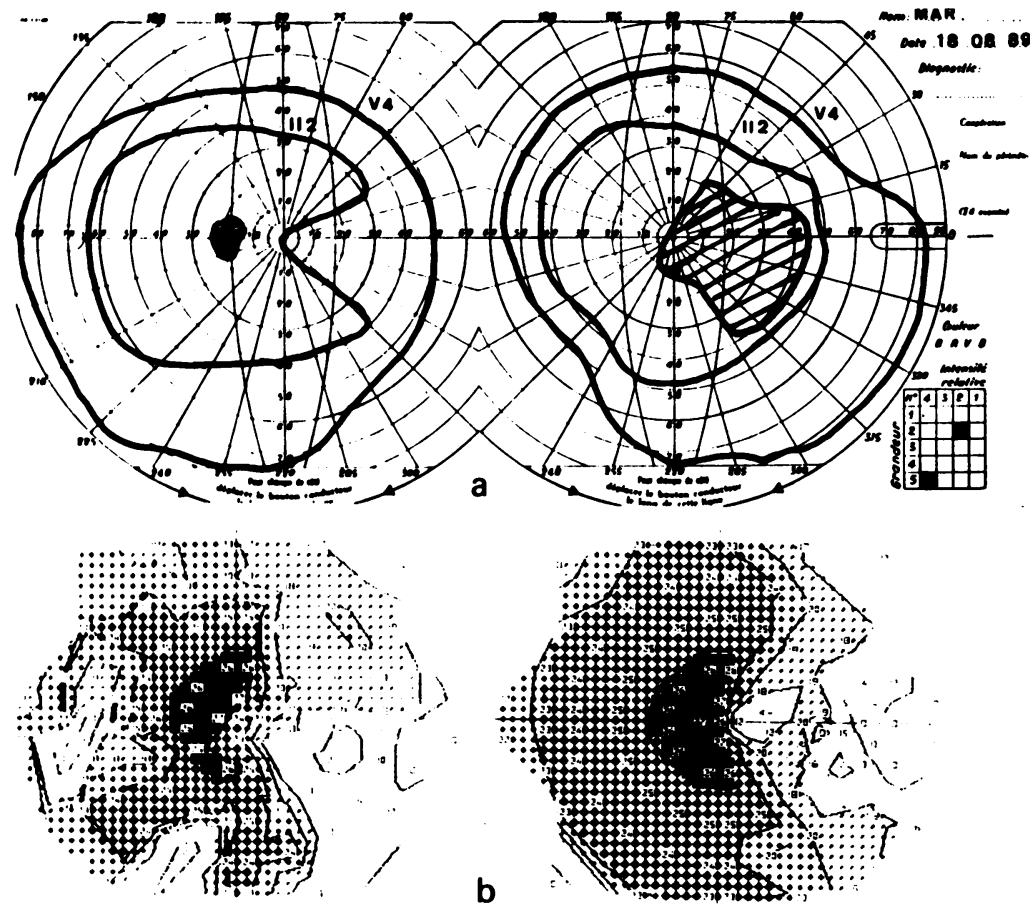

Figure 3 Case 2. Visual field chart showing right homonymous sectoranopia. a: Goldmann perimetry. $b$ : Automated perimetry.

He was responsible for a driving collision and later noticed disabilities with reading. In the past he had suffered from asthma, Raynaud's syndrome, and polyarteritis nodosa. His visual acuity was 20/30 in both eyes. A perimetric study (Fig 3) disclosed a right incongruous homonymous horizontal sectoranopia by both techniques (Goldmann and AP). On automatic perimetry the defect was larger but less characteristic of a sectoranopia. The fundus was normal. The CT scan showed a sacciform aneurysm of the supraclinoid part of the left internal carotid and a subcortical hypodensity suggesting an infarction limited to the territory of the anterior choroidal artery (Fig 4).

\section{CASE 3}

A 28-year-old woman complained of nausea and diplopia for a few days. She had a bilateral VI nerve paresis and papilloedema. A diagnosis of 'benign intracranial hypertension' was made. She was obese and had been taking a lowprogesterone contraceptive pill since her last

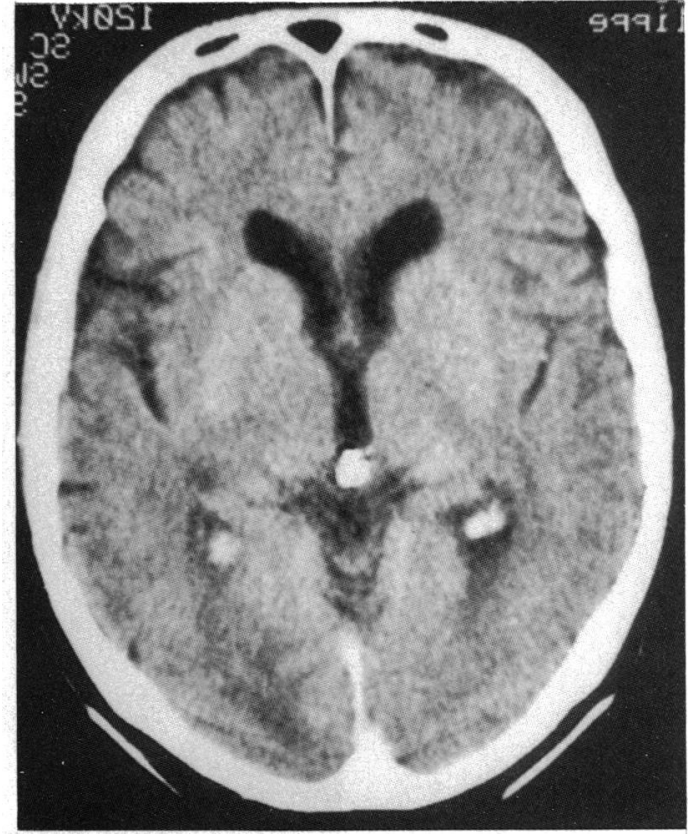

Figure 4 Case 2. Axial CT scan showing ill defined hypodensity in the left anterior choroidal artery territory (right side of picture).

delivery five months previously. She had been surgically treated for a traumatic wound of the left lateral sinus when she was 5 years old. The opening pressure of the $\mathrm{CSF}$ reached $30 \mathrm{~cm} \mathrm{H}_{2} \mathrm{O}$ and a cytochemical analysis gave normal results. Her vision was normal $(20 / 20)$ in both eyes. She had a florid papilloedema, with a marked dilatation of the papillary capillaries. The visual field (Goldmann and automatic static perimetry) (Fig 5a) disclosed an enlargement of the blind spot and a right incongruous homonymous horizontal sectoranopia. The size of the sectoranopia decreased with improvement of the intracranial hypertension. Four months later (Fig 5b) the typical visual field defect remained more apparent on automated perimetry than on the Goldmann chart. The retinal nerve fibre layer showed no abnormal features. On CT scan (Fig 6) the ventricles were small; a left parenchymatous temporal hypodensity with a retractile aspect was observed and considered to be a scar from craniocerebral trauma in childhood. The left lateral sinus was not opacified at the arteriography.
Figure 5 Case 3. Visual field, right homonymous sectoranopia. a: Top left Goldmann chart, top right automatic perimetry. $b$ : Four months later, after resolution of both the papilloedema and intracranial hypertension.

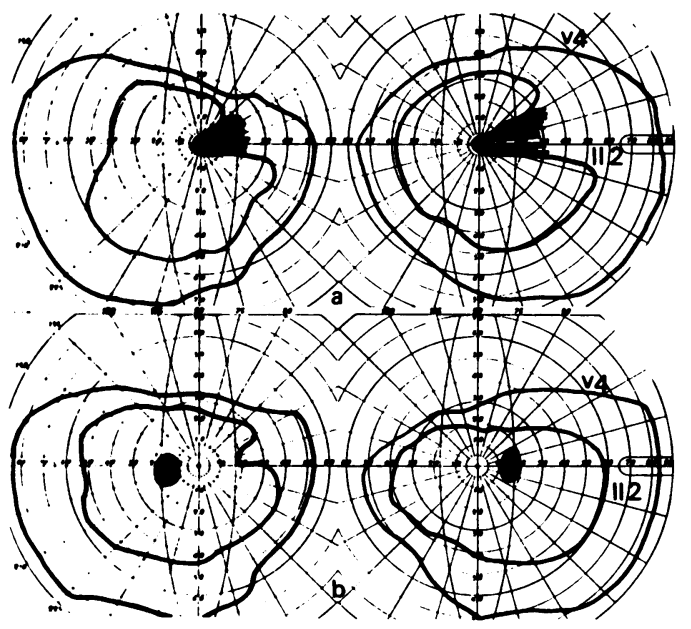

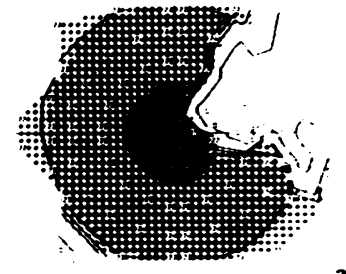

a
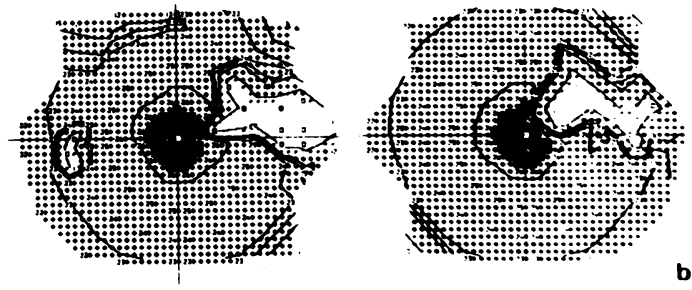


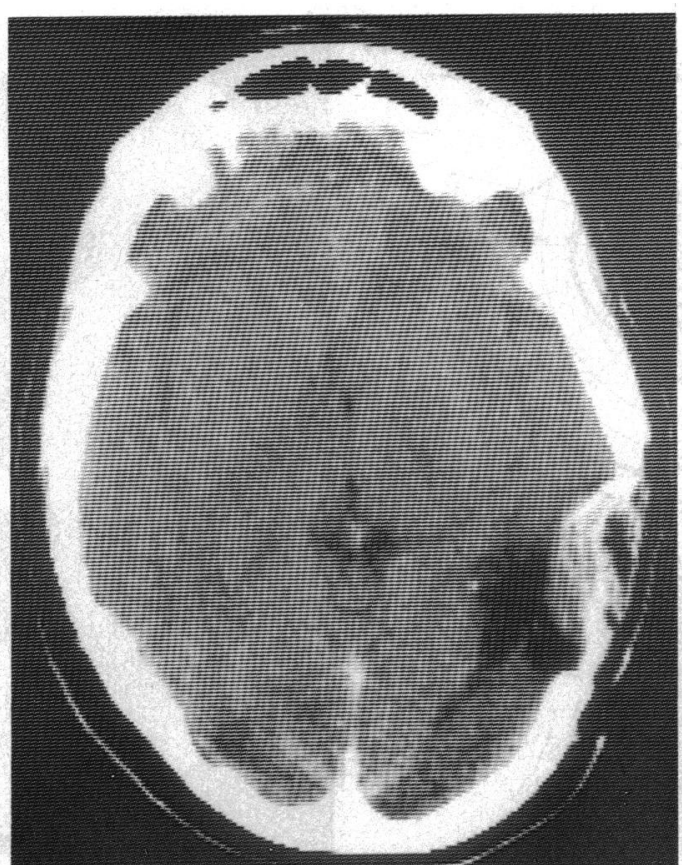

Figure 6 Case 3. Enhanced CT scan showing a left parenchymatous temporal scar (right side of picture).

\section{CASE 4}

A 25-year-old man had a surgical resection of a left temporal lobe oligodendroglioma. He had developed epilepsy at the age of 4 , with both grand mal seizures and absences. The ophthalmological investigation was undertaken after surgery when he first complained of visual disabilities. The visual acuity was normal (20/20) in both eyes. The visual field showed by both techniques (Goldmann and AP) a right horizontal incongruous homonymous sectoranopia (Fig 7a). On MRI an area of abnormal signal was located in the posterior and inferior part of the left temporal lobe from its most superficial aspect to the occipital horn (Figs 8, 9). Four months later the size of the visual field defect decreased (Fig 7b) and lost its pattern of sectoranopia on Goldmann perimetry. However, the scotoma retained a 'fish-like' aspect on AP. The appearance of the retinal nerve fibre layer was normal.

\section{Discussion}

Homonymous horizontal sectoranopia has been little documented. Since 1978 five papers ${ }^{561011}$ to our knowledge have been published reporting a total of eight cases (Table). Seven cases were investigated by CT scan and one with arteriography alone. ${ }^{3}$ The present series of four cases is the largest using modern neuroradiological investigations. All previously reported cases had left homonymous sectoranopia. They corresponded to a right hemispheric lesion of various causes - craniocerebral wound, ${ }^{7}$ astrocytoma,,$^{2510}$ vascular involvement, ${ }^{6 \times 911}$ or arteriovenous malformation. ${ }^{13510}$

Our cases had an incongruous right horizontal homonymous sectoranopia in relation to an ischaemic stroke in cases 1 and 2 and to a wound in cases 3 and 4 . All of them retained good visual acuity, ranging from $20 / 30$ to $20 / 20$, as observed in previous cases..$^{235-11}$ For three of them it was possible to match both techniques of visual field investigation - automatic static perimetry and kinetic perimetry. In general there was a good correspondence between the two methods. However, the defects on Goldmann perimetry looked more congruous than on the AP. The artificial enlargement of the central $30^{\circ}$ given by AP is the first explanation. Secondly, the mapping of the blind spot on AP accentuated the asymmetry. In our four cases the visual field pattern was right sided and the visual field defect on the right chart of AP appeared larger than on the left, probably because of the blind spot.

In fact the aspect of sectoranopia in AP is not well known. In the cases previously described ${ }^{1-11}$ all the patients but one ${ }^{6}$ had only Goldmann perimetry. In our case 2 the defect on AP was more extensive than on Goldmann but less characteristic of sectoranopia. It looked like a classical homonymous hemianopia. This statokinetic dissociation has previously been described in postchiasmal lesions. ${ }^{14}$ In the first two cases an ischaemic stroke was responsible for lesions - of the left anterior superficial sylvian territory in the first case and of the anterior choroidal artery territory in the second.

The lesions were ill defined, and anatomical correlations could not be precisely provided,
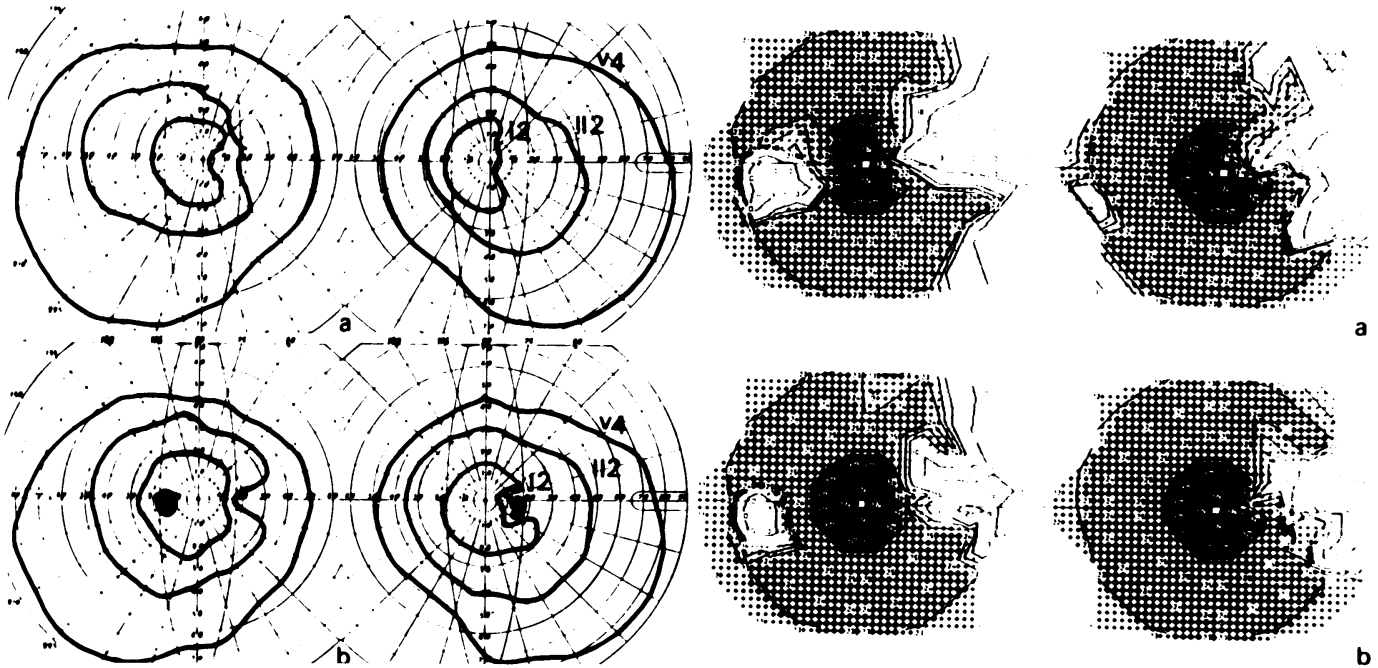

Figure 7 Case 4. Visual field. Right horizontal homonymous sectoranopia. a: One week after operation for a left temporal oligodendroglioma (left, Goldmann; right, automatic perimetry). b: same tests four months after surgery. 


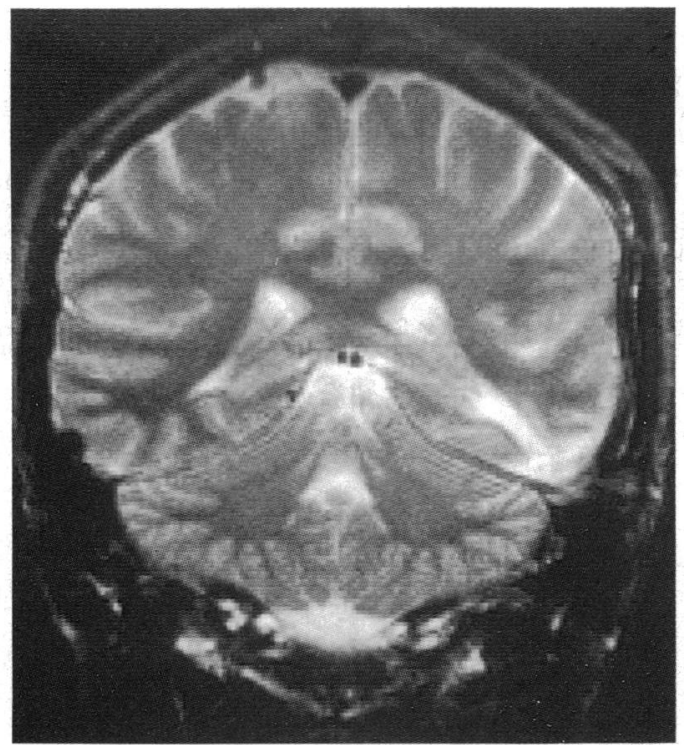

Figure 8 Case 4. Coronal T2-weighted MRI picture showing the left temporal basal postsurgical lesion (right side of picture).

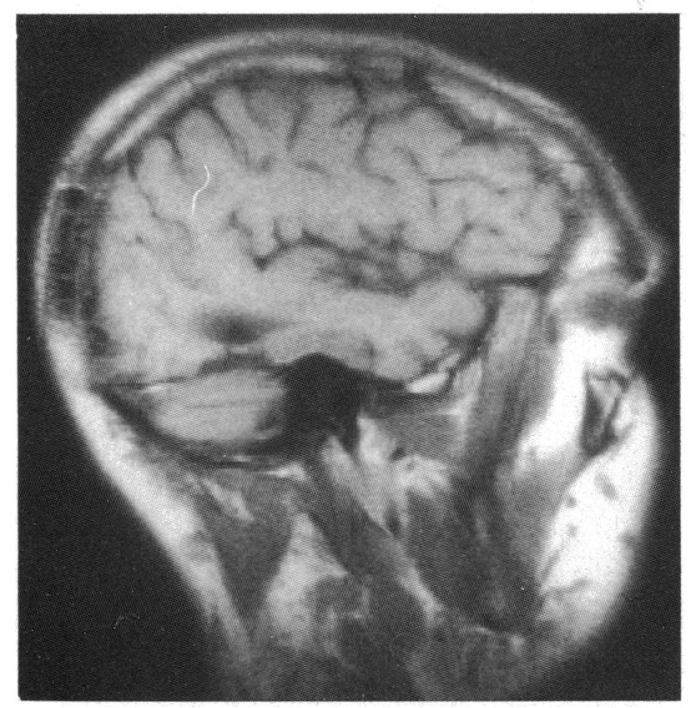

Figure 9 Case 4. Same lesion on a sagittal T1-weighted MRI picture.

especially in the first case, where the CT scan was performed early and probably showed only a part of the lesion. In cases 3 and 4 the horizontal homonymous sectoranopia resulted from, respectively, a wound of lateral sinus and resection of a temporal lobe tumour. An alteration of the optic radiations appeared likely on the CT scan, showing a superficial involvement of the temporal lobe in case 3 (Fig 6). In case 4 the lesion was located in the posterior and inferior part of the left temporal lobe. These patients had no lesion in common. Involvement of the lateral geniculate nucleus seemed very unlikely in these cases. However, an alteration of the LGN may not be easily recognised on a first CT scan when the causative mechanism is vascular. A second CT scan a few days after the beginning of the visual trouble may be necessary. ${ }^{5}$

The follow-up of our last two cases showed a partial regression of the surface of the visual field defect. In the first case it was associated with the resolution of the intracranial hypertension and in the second with the resolution of the postoperative trauma. The evolution is not always well documented. A complete return to normal of the visual field is possible. ${ }^{8}$ The visual field defect may persist without modification, ${ }^{39}$ or shrink to a small triangular paracentral scotoma, or increase with the progression of the causal disease, ${ }^{1210}$ giving a classical hemianopic pattern. ${ }^{2}$ When the LGN is involved, it seems possible to explain homonymous sectoranopia easily by anatomical arguments. ${ }^{23}$ When the lesion responsible is more diffuse and when the optic radiations are involved, anatomical correlations are less easy to effect. Since Spalding's study ${ }^{7}$ to our knowledge there have been no extensive studies permitting a precise correlation between visual field patterns and alteration of the optic radiations.

1 Holmes G. A contribution to the cortical representation of vision. Brain 1931; 54: 470-9.

2 Gunderson $\mathrm{CH}$, Hoyt WF. Geniculate hemianopia: incongruous homonymous field defects in two patients with partial lesions of the lateral geniculate nucleus. $\mathcal{F}$ Neurol Neurosurg Psychiatry 1971; 34: 1-6.

3 Frisen L, Holmegaard L, Rosencrantz M. Sectorial optic atrophy and homonymous, horizontal sectoranopia: a lateral choroidal artery syndrome? $\mathcal{f}$ Neurol Neurosurg Psychiatry choroidal artery syn

4 Frisen L. Quadruple sectoranopia and sectorial optic atrophy: a syndrome of the distal anterior choroidal artery. $\mathcal{F}$ Neuro Neurosurg Psychiatry 1979; 42: 590-4.

5 Schacklett DE, O'Connor PS, Dorwart RH, Linn D, Carte JE. Congruous and incongruous sectoral visual field defects with lesions of the lateral geniculate nucleus. Am $\mathcal{F}$ Ophthal mol 1984; 98: 283-90.

6 Nakahashi K, Takeuchi H, Sekiya Y, Ohkawa S, Yamadori A. A case of hemorrhage in the lateral geniculate body, presenting a horizontal sectoranopia. Neuro-Ophthalmolog fpn $1988 ; 5: 313-8$.

Table 1 Homonymous horizontal sectoranopia. Review of the literature

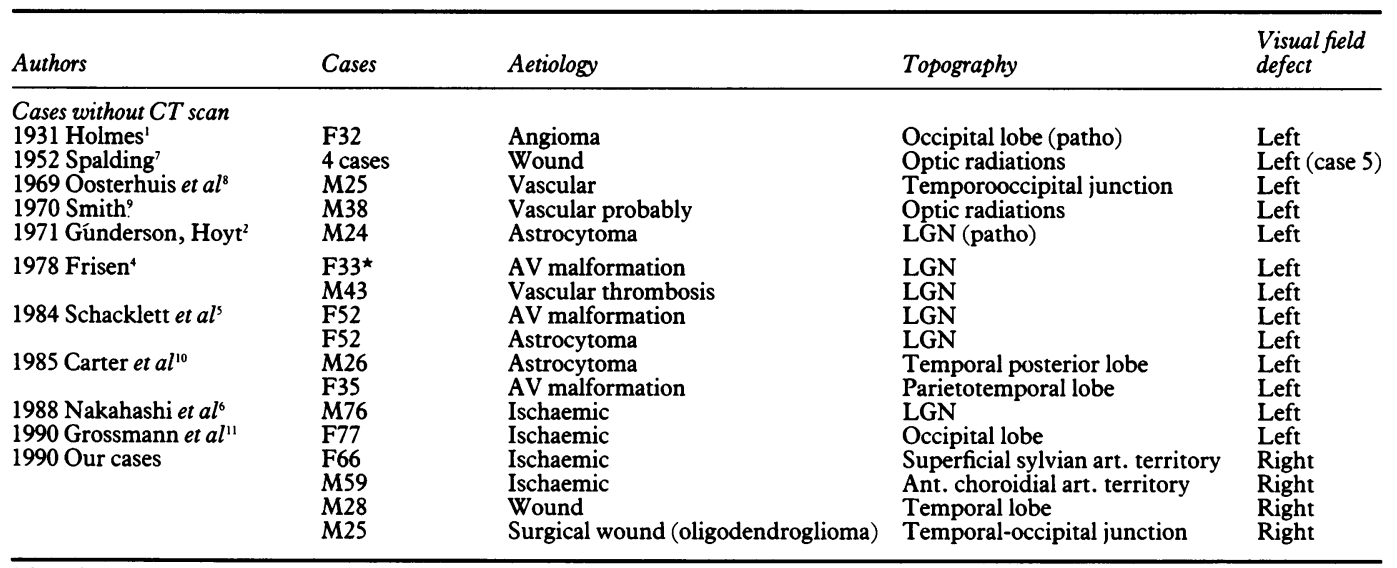

^Arteriographic investigation only.

$\mathrm{LGN}=$ lateral geniculate nucleus. $\mathrm{A} V=$ arteriovenous. $\mathrm{Patho}=$ pathological $\cdot$ study. $\mathrm{Art}=$ artery. $\mathrm{Ant}=$ anterior. 
7 Spalding JMK. Wounds of the visual pathway. Part I: The visual radiation. F Neurol Neurosurg Psychiatry 1952; 15: 99 109.

8 Oosterhuis HJGH. Ponsen L, Jonkman EJ, Mangus O. The average visual response in patients with cerebrovascular average visual response in patients with cerebrovascular

9 Smith RJS. Horizontal sector hemianopia of non-traumatic origin. $\mathrm{Br}$ f Ophthalmol 1970; 54: 208-10.

10 Carter JE, O'Connor P, Schacklett D, Rosenberg M. Lesion of the optic radiations mimicking lateral geniculate nucleus visual field defects. F Neurol Neurosurg Psychiatry 1985; 48: 982-8.

11 Grossman M, Galatte SL, Nichols CW, Grosman RI.
Horizontal homonymous sectoral field defect after ischemic infarction of the occipital cortex. Am 7 Ophthalmol 1990; 109: 234-6.

12 Grochowicki M, Vighetto A, Pissavin C. Pseudotumour cerebri: longitudinal study using contrast sensitivity and automated static perimetry. Neuro-ophthalmology 1990; 10: automated static perimetry. Neuro-ophthalmology 1990, 10:

13 Koenig F, Grochowicki M, Maugery J. Etude des fibres nerveuses rétiniennes par rétinographie en lumière bleue. Ophtalmologie (Paris) 1988; 2: 247-8.

14 Yabuki K, SaKai M, Suzumura H, Endo N, Matsuo H. A comparison of kinetic and static perimetry for lesions in the visual pathway. In: Heijl A, ed. Proceedings of the VIIIth International Perimetric Society Meeting. Amsterdam: Kugler and Ghedini, 1988-9: 15-9. 